\title{
ENVIRONMENTAL CRIMES: CRIMINAL LAW AND PROCEDURAL ASPECTS
}

\author{
Yuriy V. Frantsiforov \\ Saratov State Law Academy, Saratov, Russian Federation
}

Introduction: the public danger of ecological crimes is caused by the destruction of the natural environment, damage to the human health and activities, as ecological offences are crimes against the human being and the ecological system which reduce the lives of people and the death of other carbon life forms on earth. According to the Ministry of Internal Affairs of the Russian Federation in January - December 2016 there were registered 23,7 thousand environmental crimes. However, the statistics of environmental crimes reflects a small part of actually committed criminal offences against the public relations connected with the protection of the natural environment. The real imbalance of the situation in the environmental field and the state of the fight against environmental crimes is increasing annually, which is a consequence of the high degree of latency of these crimes, the weak state ecological control and protection of natural resources and the gaps in the environmental legislation.

In this regard, the objectives of this study are: the definition of the legal framework of ecological security of the Russian Federation, the criminal law analysis of environmental crimes, the development of recommendations of theoretical and practical nature for improving the criminal and criminal procedure legislation and the law enforcement associated with investigating environmental crimes.

Methods: the methodological basis of the study is a set of scientific methods; from among the general scientific methods there are applied the dialectical, logical, systemic, and structural-functional methods; from among the specific scientific methods there are applied the comparative law and technical methods, etc.

Results: in the work the author determines that environmental crimes in the criminal legislation are arranged in the order of those social values that are the hallmark of a democratic state: in the first row are the rights and freedoms of the individual, and then the interests of the society and state, because the natural environment is recognized as the biological basis of the health and life of the person, and that's why environmental violations are crimes against the person committed in the form of impact on the environment. The article presents the analysis of peculiarities of investigating certain crimes involving the destruction of the natural environment, the damage to the health and activities of the human.

Conclusions: as a result of the study there are given the recommendations aimed at the effective investigation of environmental crimes, feasible only under condition of an integrated approach that involves not only investigating, but also using the knowledge of experts and specialists (e.g. to identify the species of plants and organisms, or the areas of environmental pollution by the products of human technogenic activities), and carrying out operational search actions.

Key words: environmental crime, environmental protection, environmental safety, investigation of environmental crimes, investigative work, protection of the victim's rights.

\section{УДК 343.1 \\ ББК 67 \\ ЭКОЛОГИЧЕСКИЕ ПРЕСТУПЛЕНИЯ: УГОЛОВНО-ПРАВОВОЙ И ПРОЦЕССУАЛЬНЫЙ АСПЕКТЫ}

\section{Юрий Викторович Францифоров}

Саратовская государственная юридическая академия, г. Саратов, Российская Федерация

Введение: общественная опасность экологических преступлений обусловлена разрушением окружающей природной среды, причинением ущерба здоровью и деятельности человека, поскольку экологические 
посягательства - это преступления против человека и экологической системы, которые приводят к сокращению жизни людей и гибели других углеродных форм жизни на Земле. По данным Министерства внутренних дел РФ, в январе - декабре 2016 г. зарегистрировано 23,7 тыс. экологических преступлений. Вместе с тем статистика экологических преступлений отражает незначительную часть фактически совершаемых уголовно наказуемых посягательств на общественные отношения, связанные с охраной окружающей природной среды. Реальный дисбаланс ситуации в экологической сфере и состояния борьбы с экологической преступностью ежегодно увеличивается, что является следствием высокой степени латентности данных преступлений, слабого государственного экологического контроля и охраны природных ресурсов и наличия пробелов в экологическом законодательстве.

В связи с этим целями настоящего исследования являются: раскрытие содержания нормативно-правовой базы экологической безопасности Российской Федерации, уголовно-правовой анализ экологических преступлений, разработка рекомендаций теоретического и практического характера по совершенствованию уголовного, уголовно-процессуального законодательства и правоприменительной деятельности, связанной с расследованием экологических преступлений.

Методы: методологическую основу данного исследования составляет совокупность методов научного познания; из общенаучных исследовательских методов применены диалектический, логический, системный, структурно-функциональный; из частнонаучных - сравнительно-правовой и формально-юридический методы и др.

Результаты: в работе автор определяет, что экологические преступления в уголовном законодательстве расставлены в порядке тех социальных ценностей, которые являются основным признаком правового демократического государства: в первом ряду находятся права и свободы личности, а затем интересы общества и государства, поскольку природная среда признана биологической основой здоровья и жизнедеятельности человека, а потому экологические посягательства - это преступления против человека, которые совершаются в виде воздействия на среду обитания. В статье осуществлен анализ особенностей расследования отдельных преступлений, связанных с разрушением окружающей природной среды, причинением ущерба здоровью и деятельности человека.

Выводы: в результате проведенного исследования даны рекомендации, направленные на эффективное расследование экологических преступлений, осуществимое лишь при условии комплексного подхода, который связан не только с производством следственных действий, но и с использованием знаний экспертов и специалистов (например, для установления видовой принадлежности растений и организмов либо участков загрязнения окружающей среды продуктами техногенной деятельности человека), а также проведением оперативно-розыскных мероприятий.

Ключевые слова: экологические преступления, охрана окружающей среды, экологическая безопасность, расследование экологических преступлений, следственные действия, обеспечение прав потерпевшего.

\section{Введение}

Общественная опасность экологических преступлений связана с разрушением окружающей природной среды, причинением ущерба здоровью и деятельности человека, поскольку экологические посягательства - это преступления против человека и экологической системы, которые приводят к сокращению жизни людей и гибели других углеродных форм жизни на Земле.

Экологическими преступлениями признаются предусмотренные УК РФ преступления, нарушающие правила охраны природы путем негативного воздействия на природную среду, если эти деяния причинили существенный вред охраняемым отношениям [5, с. 4].
Результаты действия и последствия экологических преступлений трудно предвидеть, так как они часто невидимы и проявляются только через определенное время, однако их количество ежегодно растет.

Особую озабоченность в связи с транснациональным характером экологических преступлений выразил ХІ Конгресс ООН по предупреждению преступности и обращению с правонарушителями (Каир, 1995 г.), поставив их по своей опасности на одно из первых мест [6, с. 161].

\section{Экологическая безопасность в законодательстве РФ}

Большое внимание вопросам экологии и окружающей среды уделяется в Российской 
Федерации. Подтверждением этого является нормативно-правовая база национальной экологической безопасности.

В соответствии с основным законом РФ каждый имеет право на благоприятную окружающую среду (достоверную информацию о ее состоянии и на возмещение ущерба, причиненного его здоровью или имуществу экологическим правонарушением); каждый обязан сохранять природу и окружающую среду, бережно относиться к природным богатствам, которые являются основой развития, жизни и деятельности людей, проживающих на территории Российской Федерации (ст. 42, 58 Конституции РФ).

В Концепции долгосрочного социальноэкономического развития Российской Федерации на период до 2020 г., утвержденной распоряжением Правительства РФ от 17 ноября 2008 г. № 1662-р, в качестве основных приоритетов социальной и экономической политики нашего государства в сфере экологической безопасности выделяются улучшение состояния окружающей среды, повышение экологических стандартов, повышение обеспеченности населения качественной питьевой водой, создание эффективной системы утилизации отходов производства и потребления. Отмечается, что экономический подъем при сохранении современного уровня негативного воздействия на окружающую среду может привести к дальнейшему обострению экологических проблем. Согласно Экологической доктрине Российской Федерации обеспечение экологической безопасности, сохранение и поддержание целостности природных систем, обеспечивающих устойчивое развитие общества, повышение качества жизни и улучшение здоровья населения, разработка эффективных методов сохранения биологического разнообразия и развитие сети особо охраняемых природных территорий являются задачами государственной политики в области экологии [15].

Отношения, возникающие в области охраны окружающей среды как основы жизни и деятельности народов, проживающих на территории Российской Федерации, в целях обеспечения их прав на благоприятную окружающую среду, регулируются международными договорами РФ, Федеральным законом «Об охране окружающей среды», другими федеральными законами и иными нормативными правовыми актами РФ и ее субъектов (ч. 4 ст. 2 Федерального закона «Об охране окружающей среды» от 10 января 2002 г. № 7-Ф3).

Особое внимание вопросам охраны окружающей среды уделяют и субъекты РФ. Так, руководство ГУ МВД России по Волгоградской области и регионального управления Федеральной службы по надзору в сфере природопользования 2 августа 2016 г. подписало соглашение о взаимодействии с целью повышения эффективности совместной работы в сфере охраны окружающей среды, которое позволит объединить усилия по предупреждению, пресечению и расследованию экологических преступлений в сфере охраны окружающей среды и природопользования. Эти ведомства планируют проводить совместные рейды, проверки при участии юридических и физических лиц, осуществляющих работу в сфере обращения с отходами.

Гарантом экологической безопасности в России выступает Конституция РФ, а также УК РФ, устанавливающий ответственность за деяния, сопряженные с причинением вреда окружающей среде (глава 26 «Экологические преступления», а также ст. 358, 243, 245, 215 , 237 УК РФ).

Несмотря на то что составы данных преступлений размещены в различных главах УК РФ, все они предназначены для определения ответственности за совершение преступлений в сфере экологии и окружающей среды. Экологические отношения выступают тут дополнительным или альтернативным объектом посягательства.

Рассматривая признаки экологического преступления, посягающего на экологический порядок, следует обратить внимание не только на федеральные законы, но и на подзаконные правовые акты, такие как постановления Правительства РФ «Об утверждении Перечня нарушений законодательства в области охраны окружающей среды, представляющих угрозу причинения вреда окружающей среде, для целей государственного экологического надзора» [11], «О лимитах (предельных объемах) и квотах забора (изъятия) водных ресурсов из водного объекта и сброса сточных вод» [10], методика «Критерии 
оценки экологической обстановки территорий для выявления зон чрезвычайной экологической ситуации и зон экологического бедствия» [8], Приказ Федерального агентства по рыболовству «Об утверждении Правил рыболовства для Восточно-Сибирского рыбохозяйственного бассейна» [12].

В УК РФ экологические преступления расставлены в порядке тех социальных ценностей, которые являются основным признаком правового демократического государства: в первом ряду находятся права и свободы личности, а затем интересы общества и государства, поскольку природная среда признана биологической основой здоровья и жизнедеятельности человека, а потому экологические посягательства - это преступления против человека, которые совершаются в виде воздействия на среду обитания.

По УК РСФСР 1960 г. природная среда выступала объектом охраны «социалистической собственности», которая являлась сырьевой базой экономики нашего государства.

Следует согласиться с А.В. Бриллиантовым, который обращает внимание на то, что попытка рассматривать экологические преступления как разновидность экономических преступлений не позволяет в должной мере вскрыть специфику преступлений в сфере охраны окружающей среды, поскольку переносит центр тяжести с экологических отношений на материальные, стоимостные, что совершенно недостаточно с точки зрения современных представлений о взаимодействии общества и природы и приводит к неверному толкованию признаков этих составов на практике $[1$, c. 225$]$.

\section{Проблемы расследования экологических преступлений}

При анализе экологических преступлений следует учитывать не столько экономический ущерб, сколько ущерб, причиненный окружающей среде, который оказывает непосредственное влияние на здоровье людей и состояние иных живых существ.

При расследовании экологических преступлений важное значение имеет определение причинной связи между совершенным общественно опасным деянием и наступив- шими вредными последствиями или возникновением угрозы причинения существенного вреда окружающей среде и здоровью людей. Поэтому в обязательном порядке необходимо устанавливать, не вызваны ли вредные последствия иными обстоятельствами, в том числе естественно-природными, и не наступили ли они вне зависимости от происшедшего нарушения [9].

Анализ уголовных дел, возбуждаемых по фактам экологических преступлений, дает понять, что субъектами данных преступлений являются чаще всего руководители либо другие должностные лица предприятий, это обусловлено тем, что основными нарушителями состояния окружающей среды являются такие промышленные предприятия, которые характеризует наличие определенных деформаций в ценностно-нормативной сфере, что выражается в стремлении выполнить план любой ценой, даже в ущерб исполнению законов об охране природы; безразличное отношение к предписаниям природоохранного законодательства, а тем самым к ущербу, причиняемому природной среде их действиями [2, с. 51].

В этом случае следует согласиться с Е.Н. Карабановой, которая полагает, что служебное экологическое преступление, совершенное должностным лицом, если оно повлекло общественно опасные последствия, следует квалифицировать по совокупности преступлений. В противном случае, если должностное лицо совершит незаконную добычу (вылов) водных биологических ресурсов или незаконную охоту, его действия повлекут более мягкую ответственность, чем другие виды превышения должностных полномочий, а потому наличие еще одного объекта преступления (в данном случае это сохранность животного мира) помимо интересов службы никак не может сделать его менее общественно опасным по сравнению с преступлением против интересов службы [3].

Основным условием эффективного расследования экологического преступления, производимого в форме дознания (ч. 1 ст. 250 , ч. 1 ст. 251 , ч. 1 ст. 252 , ст. 253 , ч. 1 ст. 254 , ст. $256-258$, ч. 1 ст. 258.1 , ч. 1 ст. 260 , ч. 1 ст. 261, ст. 262 УПК РФ) либо в форме предварительного следствия (ст. 215, 237, 246-249, 
ч. $1-3$ ст. 250 , ч. $2-3$ ст. 251 , ч. $2-3$ ст. 252 , ч. $2-3$ ст. 254 , ст. 255 , ч. $2-3$ ст. 258.1 , ст. 358 УПК РФ), служит своевременное выявление факта совершения данного преступления.

Например, преступления, связанные с незаконной рубкой либо уничтожением или повреждением лесных насаждений (ст. 260-261 УК РФ), зачастую выявляются лишь по результатам космического мониторинга по истечении длительного времени с момента совершения преступления. Так, прокуратурой Иркутской области в ходе изучения приостановленных уголовных дел установлено, что около $79 \%$ таких дел возбуждено по материалам лесничеств, переданным в органы внутренних дел спустя продолжительное время с момента совершения преступления; из них $25 \%$ выявлены в ходе космического мониторинга, которым устанавливаются преступления, совершенные более 1,5-2 лет назад. В результате имевшиеся на месте преступления следы безвозвратно утрачиваются, перспективы раскрыть преступления практически отсутствуют [7, с. 94].

Эффективность расследования экологических преступлений реализуется лишь при условии комплексного подхода, который связан не только с производством следственных действий, но и с использованием знаний экспертов и специалистов (например, для установления видовой принадлежности растений и организмов либо участков загрязнения окружающей среды продуктами техногенной деятельности человека) и проведением оперативно-розыскных мероприятий.

Проблемы расследования экологических преступлений часто связаны с отсутствием специальной техники для осуществления оперативно-розыскных действий либо для выявления факта совершения преступления, а также вызваны недостатком специальных знаний должностных лиц (следователя и дознавателя), полномочных осуществлять осмотр места происшествия, обусловленного сообщением об экологическом преступлении.

Для возбуждения уголовного дела по экологическим преступлениям необходимо наличие не только установленного уголовно-процессуальным законом повода (ч. 1 ст. 140 УПК РФ), но и достаточного основания, указывающего на признаки экологического пре- ступления. Для этого необходимо проверить, насколько соответствует сообщение о преступлении фактическим данным установленного события, и с этой целью провести ряд следственных действий, разрешенных уголовно-процессуальным законодательством, до возбуждения уголовного дела.

При проверке сообщения об экологическом преступлении дознаватель, орган дознания, следователь, руководитель следственного органа вправе (до принятия решения о возбуждении уголовного дела или отказе в его возбуждении) получать объяснения, образцы для сравнительного исследования, истребовать документы и предметы, изымать их в установленном процессуальным законом порядке, назначать судебную экспертизу, принимать участие в ее производстве и получать заключение эксперта в разумный срок, производить осмотр места происшествия, документов, предметов, трупов, освидетельствование, требовать производства документальных проверок, ревизий, а также исследования документов и предметов, привлекать к участию в этих действиях специалистов, давать органу дознания обязательное для исполнения письменное поручение о проведении оперативно-розыскных мероприятий (ч. 1 ст. 144 УПК РФ).

Для проверки наличия основания совершенного преступления следователю (дознавателю) законом предоставлено время до трех суток, которое руководитель следственного органа, начальник органа дознания по мотивированному ходатайству соответственно следователя, дознавателя вправе продлить на период до 10 суток. При необходимости производства судебных экспертиз, а также проведения оперативно-розыскных действий руководитель следственного органа по ходатайству следователя, а прокурор по ходатайству дознавателя вправе продлить это время до 30 суток с обязательным указанием на конкретные факты, послужившие основанием для продления следствия или дознания (ч. 3 ст. 144 УПК РФ).

Например, причиной низкой раскрываемости преступлений, связанных с уничтожением или повреждением лесных насаждений (ст. 261 УК РФ), служит некачественное и несвоевременное проведение осмотра места происшествия на стадии проверки сообщения 
о преступлении, в результате чего не устанавливались очаги возгораний, не изымались предметы, имеющие значение для уголовного дела (емкости со следами горючих жидкостей, различные инструменты, предметы быта и иные предметы) [7, с. 96].

Зачастую органу дознания, дознавателю, следователю, руководителю следственного органа невозможно принять решение о возбуждении уголовного дела либо об отказе в возбуждении уголовного дела по результатам рассмотрения сообщения об экологическом преступлении без назначения экспертизы и получения заключения эксперта. Однако должностными лицами в ходе досудебного производства не всегда используются потенциал экспертных подразделений и знания специалистов в области науки, техники или ремесла.

В числе процессуальных задач, решение которых связано с расследованием экологического преступления, лежат вопросы доказывания, направленные на собирание, проверку и оценку доказательств с целью установления фактических обстоятельств совершенного преступления по возбужденному уголовному делу, при помощи производства следственных действий, установленных гл. 23-27 УПК РФ.

Особое место среди всех следственных действий, осуществляемых при расследовании экологических преступлений, отводится производству неотложных следственных действий, критерием которых является незамедлительность обнаружения следов преступления, а также доказательств, требующих своевременного закрепления, изъятия и исследования.

Чаще всего производство неотложных следственных действий по экологическим преступлениям вызвано необходимостью расследования, связанного с незаконной добычей (выловом) водных биологических ресурсов (ст. 256 УК РФ), незаконной охотой (ст. 258 УК РФ), уничтожением и повреждением лесов (ст. 261 УК РФ), а также с загрязнениями земель, вод, атмосферы и морской среды вредными веществами (ст. 250, 251, 252, 254 УК РФ) $[14$, c. 68].

Так, в соответствии с требованием ч. 1 ст. 157 УПК РФ при наличии признаков преступления, по которому производство предва- рительного следствия обязательно, орган дознания в порядке, установленном ст. 146 УПК РФ, возбуждает уголовное дело и производит неотложные следственные действия. Особенность производства неотложных следственных действий заключается в том, что их осуществление возлагается на органы дознания по уголовным делам, по которым производство предварительного следствия обязательно. При наличии признаков преступления орган дознания возбуждает уголовное дело и проводит следственные действия.

Неотложные следственные действия по уголовным делам, связанным с экологическими преступлениями, производятся дознавателями органов внутренних дел, таможенными органами, органами Федеральной службы судебных приставов, органами государственного пожарного надзора Федеральной противопожарной службы, а также капитанами морских и речных судов, находящимися в дальнем плавании, руководителями геолого-разведочных партий и зимовок, российских антарктических станций и сезонных полевых баз.

В статье 119 УПК РСФСР был установлен конкретный перечень неотложных следственных действий в виде осмотра, обыска, выемки, освидетельствования, задержания и допроса подозреваемого, потерпевшего и свидетеля. В то же время в ч. 3 ст. 29 Основ уголовного судопроизводства СССР и союзных республик был более широкий перечень неотложных следственных действий, и к их числу отнесено прослушивание телефонных и иных переговоров, наложение ареста на имущество и экспертиза. В УПК РФ нет полного перечня неотложных следственных действий, а дознаватель сам вправе определить, какие следственные действия он считает неотложными, руководствуясь уголовно-процессуальным законом, для обнаружения и фиксации следов преступления, других доказательств, вызванных незамедлительностью их закрепления, изъятия и последующего исследования. Эти требования неотложности определены п. 19 ст. 5 УПК РФ, в соответствии с которой орган дознания после возбуждения уголовного дела, по которому производство предварительного следствия обязательно, вправе осуществить неотложные следственные действия. 
Таким образом, к неотложным следственным действиям при расследовании экологических преступлений следует отнести осмотр места происшествия, местности, предметов и документов, производимый для обнаружения следов преступления, выяснения иных обстоятельств, имеющих значение для уголовного дела, а также освидетельствование, допрос, обыск и выемку, которые дознаватель вправе провести на первоначальном этапе расследования дел, по которым предварительное следствие обязательно.

Как правильно пишет В.А. Михайлов, неотложные следственные действия, направленные прежде всего на раскрытие преступлений, должны производиться незамедлительно и безотлагательно, поскольку закрепление следов преступления, а вместе с этим обнаружение преступлений и лиц, их совершивших, может быть затруднено или вообще может стать невозможным [4, с. 151].

Основное назначение неотложных следственных действий по экологическим преступлениям, несмотря на кратковременность возможности их осуществления, весьма значительно, так как связано не только с обнаружением и фиксацией следов преступления, иных доказательств, требующих незамедлительного изъятия и исследования, но и с обнаружением лиц, совершивших преступление, в том числе для предупреждения и пресечения преступлений.

По смыслу ст. 119 УПК РСФСР следовал вывод, что в ходе осуществления неотложных следственных действий орган дознания не вправе выносить постановление о привлечении в качестве обвиняемого и предъявлять обвинение, а также допрашивать и проводить в отношении его иные следственные действия. Однако требования п. 19 ст. 5, ст. 40 и 157 УПК РФ определяют, что такие ограничения в действующем законодательстве отсутствуют, поскольку неотложные следственные действия - это действия, осуществляемые органом дознания после возбуждения уголовного дела, по которому производство предварительного следствия обязательно в целях обнаружения и фиксации следов преступления, а также доказательств, требующих незамедлительного закрепления, изъятия и исследования. А поскольку для осуществления выше- перечисленных задач исчерпывающий перечень следственных действий не прилагается, то к следственным действиям дознавателя можно отнести допрос подозреваемого в рамках привлечения его в качестве обвиняемого и производство иных следственных действий с его участием.

Увеличение количества следственных действий, проводимых до возбуждения уголовного дела, с целью доследственной проверки уголовно-процессуальное законодательство не допускает. Следует согласиться с Г.П. Химичевой, что расширение перечня следственных действий, проводимых до возбуждения уголовного дела, уничтожит важнейшую гарантию, ограждающую граждан от произвола в применении принуждения со стороны органов расследования, приведет к стиранию границ между рассмотрением сообщения о преступлении и предварительным расследованием, позволяющим существенно ограничить права и законные интересы личности [16].

Любое следственное действие может быть проведено только при наличии основания для его производства. Правовым основанием производства следственного действия является юридический факт, вытекающий из уголовно-процессуальных отношений участников уголовного судопроизводства и порождающий право следователя осуществить конкретное следственное действие. Процессуальным основанием производства следственного действия является следственная ситуация, определяющая необходимость установления фактических данных при помощи осуществления данного следственного действия.

Невозможность быстрого установления причинно-следственной связи происшедшего события с характером и размером общественно опасных последствий связана с определенными сложностями расследования экологических преступлений. Сложность ситуации заключается в том, что даже если экологическое преступление обнаружено, часто бывает крайне сложно определить конкретных пострадавших и действительные масштабы произошедшего события, да и экономический ущерб предельно точно установить сложно $[13$, c. $25-34]$.

Вместе с тем наступившие негативные последствия, явившиеся следствием совер- 
шенного преступления, часто связаны с причинением вреда здоровью людей или с загрязнением водоемов, воздуха, почвы, а также гибелью животного и растительного мира, а потому точное установление характера наступивших последствий, в том числе и по следам, имеет важное значение не только для выбора комплекса соответствующих первоначальных следственных действий, но и для установления вида и размера причиненного вреда $[17$, с. 688$]$.

Размер нанесенного ущерба служит основанием для установления факта наступления вредных последствий, поскольку механизм данного вида преступления складывается из многих элементов, связанных причинно-следственной связью, прежде всего из преступного поведения лиц, ответственных за соблюдение природоохранных правил.

\section{Выводы}

Проблема сохранения благоприятной окружающей среды в настоящее время остается достаточно актуальной, поскольку серьезную опасность представляют собой преступные посягательства на природную среду и ее компоненты. Деятельность по расследованию экологических преступлений попрежнему остается недостаточно эффективной. Практика расследования уголовных дел указанной категории позволяет определить такие причины сложившегося положения, как недооценка реальной опасности экологических преступлений, недостаточное знание методики расследования экологических преступлений и отсутствие в экспертных учреждениях сотрудников, специализирующихся на проведении судебно-экологической экспертизы. Однако решение задач, связанных с расследованием и разрешением уголовных дел по экологическим преступлениям, обусловлено не только регулированием меры уголовной ответственности и совершенствованием деятельности следователя, дознавателя, связанной с эффективным расследованием и обеспечением прав потерпевших от этих преступлений, но и решением вопросов профилактики, вызванной выработкой рекомендацией по недопущению совершения данных преступлений.

\section{СПИСОК ЛИТЕРАТУРЫ}

1. Бриллиантов, А. В. Уголовное право России. Части общая и особенная / А. В. Бриллиантов. - М. : Проспект, 2015. - 1184 с.

2. Дагель, П. С. Пенализация преступных посягательств на окружающую природную среду / П. С. Дагель, Т. А. Бушуева // Правоведение. 1981. - № 6. - С. 49-55.

3. Карабанова, Е. Н. Проблемы квалификации сложных служебных преступлений / Е. Н. Карабанова // Уголовное право. - 2016. - № 3. - С. 50-56.

4. Курс уголовного судопроизводства : учебник. В 3 т. Т. 2 / под ред. В. А. Михайлова. - М. ; Воронеж : Изд-во психолого-социального института : МОДЭК, 2006. - 856 с.

5. Лавыгина, И. В. Экологические преступления: уголовно-правовая характеристика и проблемы ответственности : автореф. дис. ... канд. юрид. наук / Лавыгина Ирина Васильевна. - Иркутск, 2003. - 22 с.

6. Лукашук, И. И. Международное уголовное право / И. И. Лукашук, А. В. Наумов. - М. : Спарк, 1999. $-287 \mathrm{c}$.

7. Максименко, В. А. О состоянии работы правоохранительных органов по противодействию преступлениям в сфере лесопользования / В. А. Максименко // Прокурор. - 2016. - № 2. - С. 92-97.

8. Методика «Критерии оценки экологической обстановки территорий для выявления зон чрезвычайной экологической ситуации и зон экологического бедствия» : (утв. Минприроды России 30 нояб. 1992 г.). - Доступ из справ.-правовой системы «КонсультантПлюс».

9. Постановление Пленума Верховного Суда РФ «О применении судами законодательства об ответственности за нарушения в области охраны окружающей среды и природопользования» от 18 окт. 2012 г. № 21 // Российская газета. - 2012. 31 окт. (№ 251).

10. Постановление Правительства РФ «О лимитах (предельных объемах) и квотах забора (изъятия) водных ресурсов из водного объекта и сброса сточных вод» от 10 марта 2009 г. № 223 // Собрание законодательства РФ. - 2009. - № 11. - Ст. 1318.

11. Постановление Правительства РФ «Об утверждении Перечня нарушений законодательства в области охраны окружающей среды, представляющих угрозу причинения вреда окружающей среде, для целей государственного экологического надзора» от 19 нояб. 2012 г. № 1193 // Собрание законодательства РФ. - 2012. - № 48. - Ст. 6701.

12. Приказ Федерального агентства по рыболовству «Об утверждении Правил рыболовства для Восточно-Сибирского рыбохозяйственного бассейна» от 26 нояб. 2008 г. № 347 // Российская газета. 2009. - 13 февр. (№ 25). 
13. Проблематика борьбы с экологической преступностью в научных исследованиях и судебной практике / О. Л. Дубовик, А. Л. Иванова, В. Т. Калиниченко [и др.] // Экологическое право. 2008. - № 1. - С. 25-34.

14. Проценко, С. В. Незаконное занятие рыбным промыслом в местах нереста или на миграционных путях к ним (проблемы правоприменительной практики) / С. В. Проценко // Юридический мир. - 2009. - № 4 (148). - С. 68-71.

15. Распоряжение Правительства РФ «Об Экологической доктрине Российской Федерации» от 31 авг. 2002 г. № 1225-р. - Доступ из справ.-правовой системы «КонсультантПлюс».

16. Химичева, Г. П. Уточнить процедуру доследственной проверки / Г. П. Химичева // Уголовное судопроизводство. - 2012. - № 1. - С. 23-26.

17. Яблоков, Н. П. Криминалистика / Н. П. Яблоков. - М. : Норма - Инфра-М, 2000. - 990 с.

\section{REFERENCES}

1. Brilliantov A.V. Ugolovnoe pravo Rossii. Chasti obshchaya i osobennaya [Penal Law of Russia. General and Special Parts]. Moscow, Prospekt Publ., 2015. 1184 p.

2. Dagel P.S., Bushueva T.A. Penalizatsiya prestupnykh posyagatelstv na okruzhayushchuyu prirodnuyu sredu [Penalization of Criminal Attacks against the Environment]. Pravovedenie, 1981, no. 6, pp. 49-55.

3. Karabanova E.N. Problemy kvalifikatsii slozhnykh sluzhebnykh prestupleniy [Problems of Qualification of Complex Official Misconduct]. Ugolovnoe pravo, 2016, no. 3, pp. 50-56.

4. Mikhaylov V.A., ed. Kurs ugolovnogo sudoproizvodstva: uchebnik. V 3 t. T. 2 [Criminal Justice: Textbook. In 3 vols. Vol. 2]. Moscow; Voronezh, MODEK Publ., 2006. 856 p.

5. Lavygina I.V. Ekologicheskie prestupleniya: ugolovno-pravovaya kharakteristika i problemy otvetstvennosti: avtoref. dis. ... kand. yurid. nauk [Environmental Crimes: Criminal-Legal Characteristics and Issues of Responsibility. Cand. jurid. sci. abs. diss.]. Irkutsk, 2003. 22 p.

6. Lukashuk I.I., Naumov A.V. Mezhdunarodnoe ugolovnoe pravo [International Penal Law]. Moscow, Spark Publ., 1999. 287 p.

7. Maksimenko V.A. O sostoyanii raboty pravookhranitelnykh organov po protivodeystviyu prestupleniyam $\mathrm{v}$ sfere lesopolzovaniya [On the Quality of Work of Law Enforcement Agencies on Crime Prevention in the Sphere of Forest Management]. Prokuror, 2016, no. 2, pp. 92-97.

8. Metodika "Kriterii otsenki ekologicheskoy obstanovki territoriy dlya vyyavleniya zon chrezvychaynoy ekologicheskoy situatsii $i$ zon ekologicheskogo bedstviya»: (utv. Minprirody Rossii 30 noyab. 1992 g.) [The Technique "Criteria for Evaluation of Ecological Situation of Territories for Revealing Zones of Extraordinary Ecological Situation and Zones of Ecological Disaster": Approved by the Ministry of Natural Resources of Russia on November 30, 1992)]. Access from KonsultantPlyus reference legal system.

9. Postanovlenie Plenuma Verkhovnogo Suda $\mathrm{RF} « \mathrm{O}$ primenenii sudami zakonodatelstva ob otvetstvennosti za narusheniya $v$ oblasti okhrany okruzhayushchey sredy i prirodopolzovaniya» ot 18 okt. 2012 g. № 21 [The Decree of Plenum of the Supreme Court of the Russian Federation "On the Application by Courts of Legislation on Liability for Violations in the Field of Environment Protection and Nature Management" of October 18, 2012 no. 21]. Rossiyskaya gazeta, 2012, no. 251 (October 31).

10. Postanovlenie Pravitelstva $\mathrm{RF} « \mathrm{O}$ limitakh (predelnykh obyemakh) i kvotakh zabora (izyatiya) vodnykh resursov iz vodnogo obyekta i sbrosa stochnykh vod» ot 10 marta 2009 g. № 223 [The Decree of the Government of the Russian Federation "On the Limits (Limiting Volumes) and Quotas of Obtaining (Withdrawal) Water Resources from Water Object and Sewage Discharge" of March 10, 2009 no. 223]. Sobranie zakonodatelstva $R F$ [Collected Legislation of the Russian Federation], 2009, no. 11, art. 1318.

11. Postanovlenie Pravitelstva RF «Ob utverzhdenii Perechnya narusheniy zakonodatelstva $\mathrm{V}$ oblasti okhrany okruzhayushchey sredy, predstavlyayushchikh ugrozu prichineniya vreda okruzhayushchey srede, dlya tseley gosudarstvennogo ekologicheskogo nadzora» ot 19 noyab. 2012 g. № 1193 [The Decree of the Government of the Russian Federation "On Approval of the List of Violations of Legislation in the Field of Environmental Protection, Posing Threat of Harm to the Environment, for the Purposes of State Environmental Supervision" of November 19, 2012 no. 1193]. Sobranie zakonodatelstva $R F$ [Collected Legislation of the Russian Federation], 2012, no. 48, art. 6701

12. Prikaz Federalnogo agentstva po rybolovstvu «Ob utverzhdenii Pravil rybolovstva dlya VostochnoSibirskogo rybokhozyaystvennogo basseyna» ot 26 noyab. 2008 g. № 347 [The Order of the Federal Agency on Fishery "On Approval of the Fishing Rules for the East-Siberian Fishery Basin" of November 26, 2008 no. 347]. Rossiyskaya gazeta, 2009, no. 25 (February 13).

13. Dubovik O.L., Ivanova A.L., Kalinichenko V.T., et al. Problematika borby s ekologicheskoy prestupnostyu $\mathrm{v}$ nauchnykh issledovaniyakh i sudebnoy praktike [The Problem of Environmental Crime Prevention in Scientific Research and Court 


\section{ГЛАВНАЯ ТЕМА НОМЕРА}

Practice]. Ekologicheskoe pravo, 2008, no. 1, pp. 25-34.

14. Protsenko S.V. Nezakonnoe zanyatie rybnym promyslom $\mathrm{v}$ mestakh neresta ili na migratsionnykh putyakh k nim (problemy pravoprimenitelnoy praktiki) [Illegal Fishing in Spawning or Migratory Ways (problems of law enforcement practice)]. Yuridicheskiy mir, 2009, no. 4(148), pp. 68-71.

15. Rasporyazhenie Pravitelstva $\mathrm{RF} « \mathrm{Ob}$ Ekologicheskoy doktrine Rossiyskoy Federatsii» ot 31 avg. 2002 g. № 1225-r [The Decree of the
Government of the Russian Federation "On Ecological Doctrine of the Russian Federation" of August 31, 2002 no. 1225-r]. Access from KonsultantPlyus reference legal system.

16. Khimicheva G.P. Utochnit protseduru dosledstvennoy proverki [Clarifying the Procedure of Preliminary Investigation]. Ugolovnoe sudoproizvodstvo, 2012, no. 1, pp. 23-26.

17. Yablokov N.P., ed. Kriminalistika [Criminalistics]. Moscow, Norma - Infra-M Publ., 2000. $990 \mathrm{p}$.

\section{Information about the Author}

Yuriy V. Frantsiforov, Doctor of Juridical Sciences, Professor, Department of Criminal Procedure, Saratov State Law Academy, Volskaya St., 1, 410056 Saratov, Russian Federation, franciforov@mail.ru.

\section{Информация об авторе}

Юрий Викторович Францифоров, доктор юридических наук, профессор кафедры уголовного процесса, Саратовская государственная юридическая академия, ул. Вольская, 1, 410056 г. Саратов, Российская Федерация, franciforov@mail.ru. 